\title{
Role of Wall Phosphomannan in Flocculation of Saccharomyces cerevisiae
}

\author{
By PERERA M. JAYATISSA* AND A. H. ROSE \\ Zymology Laboratory, School of Biological Sciences, Bath University, Bath BA2 $7 A Y$
}

(Received I March 1976)

\begin{abstract}
SUMMAR Y
Treatment with $60 \%$ hydrofluoric acid (HF) removed most of the phosphorus and small amounts of mannan, glucan and protein from walls of two nonflocculent strains (NCYC366 and NCYCI004) and two flocculent strains (NCYCIO05 and NCYCI063) of Saccharomyces cerevisiae. Organisms of all strains showed increased flocculating ability following HF treatment. Flocculation of untreated organisms of NCYCIOO5 and NCYCIO63, and of HF-treated organisms of all four strains, declined appreciably when they were washed in deionized water, with or without EDTA, and the flocculation was measured in deionized water instead of in 0.05 M-sodium acetate containing $\mathrm{Ca}^{2+}$. Treatment with $\mathrm{I}, 2$-epoxypropane also caused a decrease in the flocculating ability of these organisms. Extracting the lipids from organisms of strains $\mathrm{NCYC}_{3} 66$ and NCYCIOO4 had no effect on their flocculating ability, but decreased the flocculating ability of organisms of strains NCYCIOO5 and NCYCI063. pH-electrophoretic mobility curves of untreated and HF-treated organisms confirmed the loss of wall phosphate by HF treatment, and indicated that HF treatment had little effect on the content of protein carboxyl groups in the outer wall layers. Mannose at $0.22 \mathrm{M}$ completely prevented floc formation by organisms of strain NCYCI063; but, even at $0.33 \mathrm{M}$, it had very little effect on floc formation by HF-treated organisms of strains NCYC366 and NCYCI063. Organisms of all four strains bound fluorescein-conjugated concanavalin $\mathrm{A}$ to the same extent after treatment with $\mathrm{HF}$ as before, but this treatment led to a greatly diminished binding of fluorescein-conjugated antiserum raised against organisms of strain NCYC366. The results indicate that phosphodiester linkages in yeast-wall mannan are not involved in bridge formation through $\mathrm{Ca}^{2}+$ during floc formation and that this arises principally through carboxyl groups.
\end{abstract}

\section{INTRODUCTION}

Flocculation is the term used to describe the property expressed by certain strains of Saccharomyces cerevisiae or S. carlsbergensis when, at the end of a brewery fermentation, they spontaneously aggregate to form flocs which sediment in the fermentation vessel (for reviews, see Rainbow, 1970; Stewart, 1975). Although the mechanism of flocculation has interested yeast biochemists for many years, the molecular basis of the phenomenon is far from being understood. Two types of aggregation mechanism have been advocated. The first suggests that one or more anionic components in the walls of adjacent cells are linked through salt bridges, and there is general agreement that the bivalent cation involved is $\mathrm{Ca}^{2+}$. Other workers believe that the aggregation mechanism is more complex, and involves not only salt bridges but also other types of secondary interaction between components in yeast walls.

* Present address : C.I.S.I.R., 363 Bauddaloka Mawata, Colombo 7, Sri Lanka. 
There is also a division of opinion on the nature of the anionic wall components involved. Harris (1959) postulated intercellular bonding in which bivalent cations link carboxyl groups in adjacent cells. Mill (1964 $b$ ) largely agreed with Harris (1959) but suggested that the floc is stabilized by co-operative hydrogen bonding involving hydroxyl groups on the cell-surface polysaccharide. Recent work by Stewart, Russell \& Garrison (I975) furnished additional evidence for the formation of carboxyl- $\mathrm{Ca}^{2}+$ complexes in yeast flocs, and they suggested that the carboxyl groups involved are in acidic wall proteins. Lyons \& Hough (1970 a, $b$, 1971), on the other hand, believe that the anionic groups involved are mainly, if not solely, in the phosphodiester linkages in the wall mannan (Ballou, 1974, 1976). They found that walls of flocculent strains of $S$. cerevisiae contain more phosphorus in the outer layers of the wall than non-flocculent strains, and bind twice as much $\mathrm{Ca}^{2+}$ as do walls of non-flocculent strains. Although they found that esterification of carboxyl groups in the wall with I,2epoxypropane caused a drop of only $20 \%$ in the calcium-binding capacity of the wall, they failed to find a correlation between the amounts of acidic amino-acid residues in the walls and the flocculating ability of organisms from which they were derived. Lyons \& Hough (I97I) concluded that the capacity of strains of S. cerevisiae to flocculate is proportional to the density of phosphate groups in the phosphomannan-protein layer of the wall.

The present paper reports findings which allow an assessment to be made of the relative contributions from acidic amino-acid residues and phosphodiester linkages in the flocculation of $S$. cerevisiae. A technique was used which excises from the wall mannan phosphodiester linkages and mannose residues distal to the phosphodiester linkages. The technique, in which organisms and walls are treated with hydrofluoric acid (HF), has previously been used to excise phosphodiester linkages from other polymers including teichoic acids (Glaser \& Burger, 1964; Archibald, Baddiley \& Shaukat, 1968) and bacterial phospholipids (Shaw \& Stead, I974), as well as from mannan extracted from S. cerevisiae (Cawley, Harrington \& Letters, 1972). The reaction catalysed by HF may be represented as :<smiles>[M][M][M][M][M][M][M][M][M][M]</smiles>

\section{METHODS}

Organisms. Four strains of Saccharomyces cerevisiae, NCYC366, NCYC1004, NCYCI005 and NCYCIO63, were used in this study. Stock cultures were maintained at $4{ }^{\circ} \mathrm{C}$ on slopes containing $(\%$, w/v) $: 0.3$ malt extract, 0.3 yeast extract, 0.5 mycological peptone, $\mathrm{I} \cdot 0$ glucose, and 2.0 agar (MYGP medium, pH 4.5; Wickerham, I95I).

Experimental cultures. Organisms were grown batchwise in I 1 portions of MYGP medium in 21 round flat-bottomed flasks. Batches of medium were inoculated with a portion from a $24 \mathrm{~h}$ culture in MYGP medium containing approximately $10.0 \mathrm{mg}$ dry wt organisms. Cultures were incubated at $30^{\circ} \mathrm{C}$ with stirring, as described by Patching \& Rose (1970). Organisms were harvested from stationary-phase cultures, containing $\mathrm{I} \cdot 3$ to $\mathrm{I} \cdot 5 \mathrm{mg}$ dry wt $\mathrm{ml}^{-1}$, by centrifuging at $0^{\circ} \mathrm{C}$ at $2000 \mathrm{~g}$. They were washed twice with distilled water and, unless otherwise indicated, freeze-dried and stored at $4{ }^{\circ} \mathrm{C}$ over silica gel in a vacuum desiccator. 
Measurement of flocculation. The flocculating ability of organisms was measured by a modification of the methods used by Mill (1964a) and Greenshields et al. (1972). Organisms

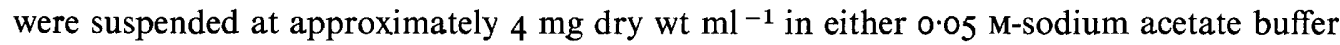
$\mathrm{pH} 4.5$ containing $0 . \mathrm{I} \%(\mathrm{w} / \mathrm{v}) \mathrm{CaCl}_{2}$ or in deionized water adjusted to the same $\mathrm{pH}$. A portion $(3 \mathrm{ml}$ ) of this suspension was placed in a cuvette ( $\mathrm{I} \mathrm{cm}$ path length), which was then inverted two or three times to bring the organisms into uniform suspension. Using a PyeUnicam SPI 800 spectrophotometer with an automatic recorder, the extinction of the suspension at $600 \mathrm{~nm}$ was measured over a period of 5 to Io min against an appropriate blank. Extinction values were converted to $\mu \mathrm{g}_{\text {dry }} \mathrm{wt} \mathrm{ml}^{-1}$ and a graph was plotted of dry wt $\mathrm{ml}^{-1}$ against time. Sedimentation rates were calculated by measuring the maximum slope of the curve, and are expressed as $\mu \mathrm{g}$ dry wt $\mathrm{ml}^{-1} \mathrm{~min}^{-1}$.

Preparation of walls. Yeast walls were prepared by shaking a suspension of organisms (200 $\mathrm{mg}$ dry wt in $20 \mathrm{ml} \mathrm{O} . \mathrm{I} \mathrm{M}-\mathrm{KH}_{2} \mathrm{PO}_{4}$ ) with glass beads (30 $\mathrm{g} ; 0 . \mathrm{I} 7$ to $0.18 \mathrm{~mm}$ diam.; Glasperlen, from Braun, Melsungen, West Germany) for 2 to 3 min in a Braun homogenizer, while cooling the glass homogenizer bottle with liquid $\mathrm{CO}_{2}$. Walls were separated from the suspension of disrupted organisms by the method of McMurrough \& Rose (1967), and washed Io times with ice-cold water. The absence of intact organisms from the wall preparations was established by microscopic examination of methylene blue-stained preparations (Chattaway, Holmes \& Barlow, 1968). Walls were freeze-dried and stored at $4{ }^{\circ} \mathrm{C}$ over silica gel in a vacuum desiccator.

Treatment of organisms and walls with $H F$. Freeze-dried organisms or walls (I00 $\mathrm{mg}$ ) were incubated with 58 to $62 \%(\mathrm{v} / \mathrm{v}) \mathrm{HF}(\mathrm{I} \mathrm{ml})$ at ${ }^{\circ}{ }^{\circ} \mathrm{C}$ in a polythene tube for 3 to $5 \mathrm{~h}$. The tube was then cooled to about $-60^{\circ} \mathrm{C}$ in a bath containing solid $\mathrm{CO}_{2}$ and ethanol, and a calculated quantity of $2 \mathrm{M}-\mathrm{KOH}$ was added to largely neutralize the HF. The mixture was then allowed to warm slowly to $0^{\circ} \mathrm{C}$ and the $\mathrm{pH}$ value was adjusted to $7 \cdot 0$ with solid $\mathrm{K}_{2} \mathrm{CO}_{3}$. The organisms or walls were separated by centrifuging and washed at least five times with water. Washed organisms or walls were freeze-dried and stored at $4{ }^{\circ} \mathrm{C}$ over silica gel in a vacuum desiccator.

Analysis of walls. Glucan and mannan contents of walls were determined by the method of McMurrough \& Rose (1967) which is a modified sulphuric acid-carbazole differential extinction method. Total nitrogen content of walls was determined by the micro-Kjeldahl technique, using a colorimetric method (Fraser \& Russell, I969) to determine the $\mathrm{NH}_{4}{ }^{+}$ content of the micro-Kjeldahl digest. The protein content was calculated by multiplying the value for the nitrogen content by 6.3. The method of Chen, Toribara \& Warner (1956) was used to determine the phosphorus content of walls.

Measurement of electrophoretic mobility. The electrophoretic mobility of organisms at different $\mathrm{pH}$ values was measured using a Cytopherometer (Zeiss, Oberkochen, West Germany) and a modification of the method of Somers \& Fisher (1967). Movement was timed over $80 \mu \mathrm{m}$ in both directions (current reversal). Each mobility value was the mean of at least 20 observations. Mobilities of organisms were measured using suspensions ( $\mathrm{IO} \mathrm{ml}$ ) containing approximately $0.5 \mathrm{mg}$ dry wt $\left(10^{7}\right.$ organisms) $\mathrm{ml}^{-1}$. The buffers used (Gittens \& James, I963) were $\mathrm{NaCl} / \mathrm{HCl}\left(\mathrm{pH} \mathrm{I}_{5} \cdot 5\right.$ to $2 \cdot 0$ ) or $\mathrm{NaCl} /$ sodium acetate/sodium barbiturate/

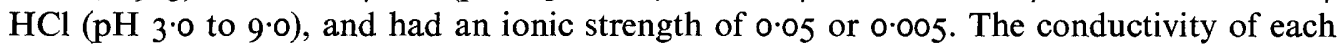
buffer was measured using a Griffin conductivity bridge (Griffin \& George, Wembley, Middlesex).

Staining with fluorescein-conjugated antibody. Antiserum against S. cerevisiae NCYC366 was prepared by injecting healthy adult rabbits (approx. 2.5 to $3.0 \mathrm{~kg} \mathrm{wt}$ ) with organisms grown in Sabouraud dextrose broth at $30{ }^{\circ} \mathrm{C}$ and harvested in the stationary phase of 
growth, as described by Klaushofer \& Dorfwirth (1970). Immunofluorescent staining of organisms was carried out using the sandwich technique described by Richards \& Cowland (1967); stained smears were examined using a Leitz Orthoplan microscope (Leitz, Wetzlar, West Germany) fitted with a fluorescence vertical illuminator.

Staining with fluorescein-conjugated concanavalin A. Fluorescein was conjugated to concanavalin A by the method of Tkacz, Cybulska \& Lampen (I97I), and the conjugate was purified using a column of Sephadex G-75 (Pharmacia). Strains of S. cerevisiae were stained with the fluorescein-conjugated concanavalin A using the method of Tkacz et al. (1971). Stained smears were examined microscopically in the same manner as preparations stained with fluorescein-conjugated antibody.

Lipid extraction. Lipids were extracted from organisms by the method of Hunter \& Rose (1972). After extraction, organisms were washed in distilled water.

Chemicals. All chemicals, except those listed below, were of Analar grade, obtained from BDH. Hydrofluoric acid ( 58 to $62 \%$ w/v) was from Fisons Scientific Apparatus, Loughborough, Leicestershire. All ingredients of MYGP medium except malt extract were obtained from Oxoid. Malt extract was purchased from Munton \& Fison, Stowmarket, Suffolk, concanavalin A from Pharmacia, and fluorescein isothiocyanate from Calbiochem. Fluorescein-conjugated anti-rabbit (sheep) immunoglobulin was supplied by Wellcome Reagents, Beckenham, Kent.

\section{RESULTS}

\section{Effect of HF on wall composition}

Walls from the strains of $S$. cerevisiae used in this study differed slightly in their contents of glucan, mannan, protein and phosphorus (Table I). These components accounted for 84 to $91 \%$ of the dry weight of all walls, the remainder presumably being lipid and glucosamine residues, neither of which was determined. Treating walls with HF led to the loss of 7 to $10 \%$ of the dry weight. About half of this loss can be attributed to the disappearance of a large proportion of the phosphorus from the walls, together with some mannan and a little glucan. Walls of strain NCYCIO63 also lost some protein during treatment with HF.

\section{Flocculation of organisms before and after treatment with $\mathrm{HF}$}

Sedimentation rates were routinely measured on freeze-dried organisms, since both freshly-harvested and freeze-dried organisms formed flocs and sedimented at the same rate. Organisms of strains NCYC366 and NCYCIOO4 sedimented much more slowly than those of strains NCYCI005 and NCYCI063 (Table 2), which is in general agreement with the findings of Lyons \& Hough (1970 $b$ ). Treatment with HF increased the sedimentation rates of organisms of all four strains, but proportionately more so with strains NCYC366 and NCYCI004. When the rates of floc sedimentation of untreated organisms of strains NCYCI005 and NCYCI063, and of HF-treated organisms of all four strains, were measured in deionized water after washing in the same, they were appreciably lower, and with untreated organisms of strains NCYCIOO5 and NCYCI063 were of the order obtained with untreated and unwashed organisms of strains NCYC366 and NCYCIO04. The reduction in the rates was even greater when HF-treated organisms were washed in ro mM-EDTA before measuring the rates in deionized water (Table 2). Organisms which had been deflocculated by washing in deionized water or EDTA regained the ability to form flocs when $\mathrm{CaCl}_{2}(0 \cdot \mathrm{r} \%$, w/v) was included in the deionized water in which the rate was measured. Treating organisms with the esterifying agent I,2-epoxypropane (Mill, I964 $b$; Lyons \& Hough, I $970 b$ ) lowered the rate of floc sedimentation of all four strains after they had been treated with HF. This I,2-epoxypropane 
Wall phosphomannan and flocculation in yeast

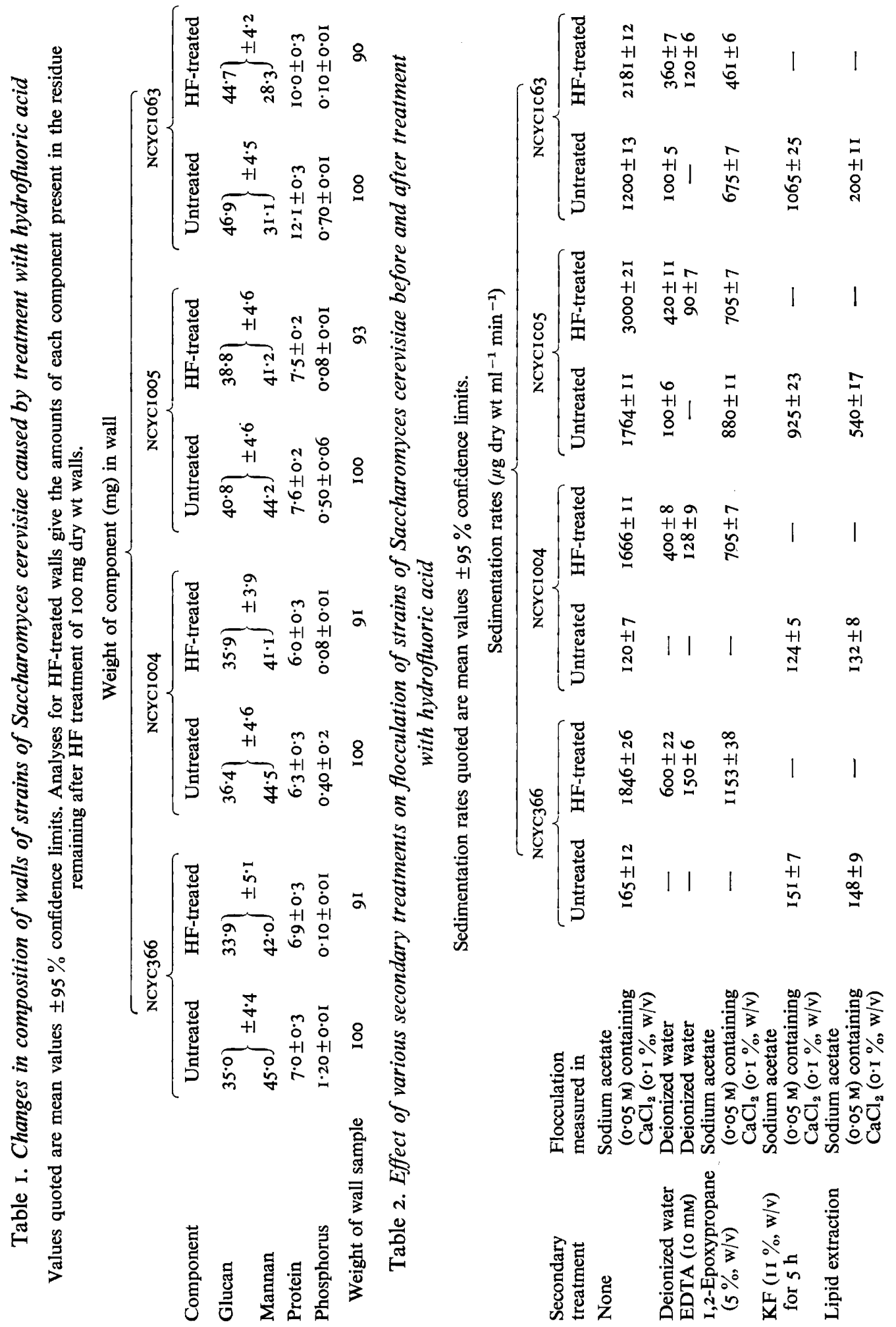




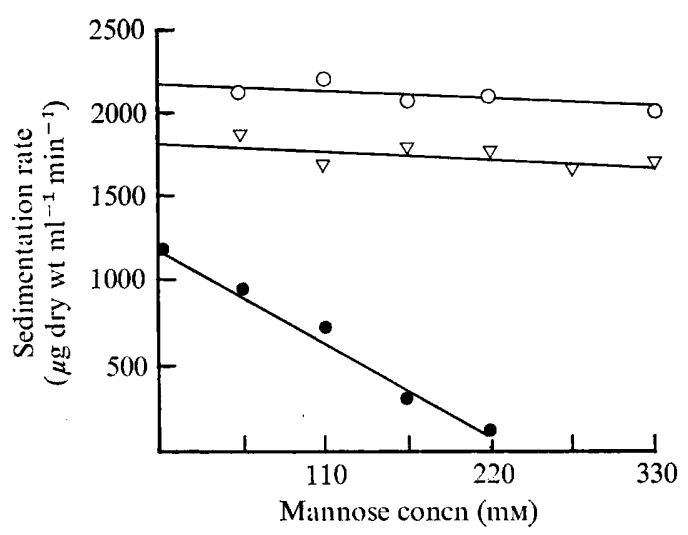

Fig. I. Effect of mannose on the sedimentation rates of untreated and HF-treated organisms of Saccharomyces cerevisiae: $\bullet$, Untreated organisms of strain NCYCI063; $\mathrm{O}, \mathrm{HF}$-treated organisms of strain NCYCI 063 ; and $\nabla$, HF-treated organisms of strain NCYC366.
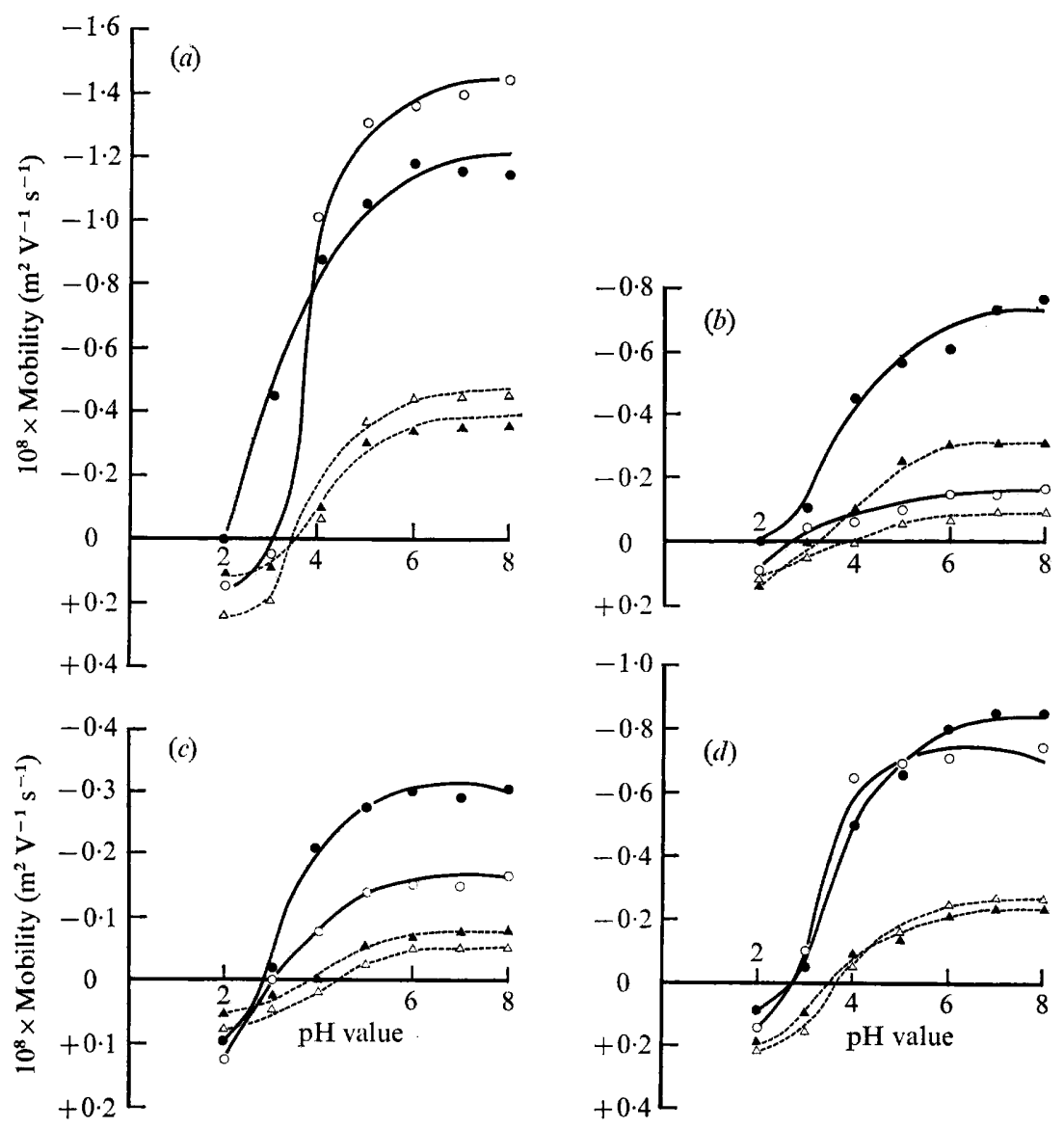

Fig. 2. pH-mobility curves of untreated and HF-treated organisms of Saccharomyces cerevisiae: (a) NCYC366; (b) NCYCIOO4; (c) NCYCIOO5; and (d) NCYCIO63. Mobilities of $(0,0)$ untreated organisms, and $(\triangle, \Delta)$ HF-treated organisms were measured in buffers with ionic strengths of $(O, \triangle) 0.005$, and $(\mathbf{\Delta}, \Delta) 0.05$. Mobility values quoted are the means of at least 20 observations. The standard error of the means was less than $2 \%$. 
treatment also lowered the sedimentation rates of untreated organisms of strains NCYCI005 and NCYCI063 ; the effect on untreated organisms of strains NCYC366 and NCYCroo4 was such that the rates were too slow to be measured accurately.

As some of the effects following treatment of yeasts with HF may have been caused by retention of $\mathrm{F}^{-}$in the envelope layers of organisms, untreated organisms were suspended in II $\%(w / v) ~ K F$ for $5 \mathrm{~h}$, and their rates of floc sedimentation were then measured. This treatment, however, had no measurable effect on the rates for organisms of any of the strains except NCYCI005, for which the rate was reduced to about half of that for organisms that had not been suspended in KF solution (Table 2).

Since the phosphodiester group in phospholipids is susceptible to the action of HF (Shaw \& Stead, 1974) and yeast walls may contain small amounts of phospholipid, the effect of lipid extraction on the rates of floc sedimentation was examined. Lipid-depleted organisms of strains NCYC366 and NCYCIOO4 formed flocs and sedimented at the same rate as untreated organisms, but the rate at which organisms of the more flocculent strains sedimented after lipid extraction was appreciably reduced (Table 2).

Mannose is very effective in preventing floc formation by $S$. cerevisiae when included in the suspending buffer (Eddy, I955). When this sugar was included in the buffer at $0.22 \mathrm{M}$, it virtually prevented floc formation by the flocculent strain NCYCrO63 (Fig. I). However, the presence of mannose up to $0.33 \mathrm{M}$ in the buffer had little retarding effect on the sedimentation rates of HF-treated organisms of strains NCYCrO63 or NCYC366 (Fig. I). Data on the effect of mannose on the flocculation of untreated organisms of strain $\mathrm{NCYC}_{3} 66$ are not included, since in the presence of mannose their sedimentation rate was too slow to permit accurate measurement.

\section{pH-mobility curves of untreated and HF-treated organisms}

Figure 2 shows the effect of $\mathrm{pH}$ value on the electrophoretic mobility, in buffers of ionic strength 0.05 or 0.005 , of untreated and HF-treated organisms of all four strains of S. cerevisiae. Mobility at $\mathrm{pH} 4^{\circ} 0$, which is attributable to ionization of phosphodiester groups (Eddy \& Rudin, I958), was greatly decreased in HF-treated organisms, and with organisms of strain NCYCIOO4 in buffer with an ionic strength of 0.05 and of strain NCYCI005 at both ionic strengths, mobility at this $\mathrm{pH}$ value was almost completely absent. The mobility attributable to protein in the wall surface, a measure of which is the difference between the mobilities at $\mathrm{pH} 7.0$ and 3.0 (Eddy \& Rudin, I958), was also reduced by HF treatment, but not nearly to the same extent as that for which phosphodiester linkages are responsible. Mobilities in buffers of ionic strength 0.05 and 0.005 have been attributed to groups which lie at depths of 1.4 and $4.2 \mathrm{~nm}$, respectively, from the wall surface (Fisher, 1975). Organisms of strains NCYCIOO4 and NCYCIOO5 generated appreciably fewer ionogenic groups in the deeper surface shell of the wall, whereas organisms of strain NCYCIO63 and to some extent of $\mathrm{NCYC}_{3} 66$ had approximately the same mobility at different $\mathrm{pH}$ values irrespective of the ionic strength of the buffer.

\section{Binding of fluorescein-conjugated concanavalin $A$ and antibody by untreated and $H F$-treated organisms}

Organisms of all four strains of $S$. cerevisiae bound fluorescein-conjugated concanavalin A to the same extent after treatment with HF as before. However, binding of fluoresceinconjugated antiserum raised against $S$. cerevisiae NCYC366 was appreciably less in all four strains after HF treatment (scored as $I+$ compared with untreated organisms at $4+$ ). 


\section{DISCUSSION}

Treatment of walls with HF led to the removal of 80 to $90 \%$ of the wall phosphorus which it is assumed is located mainly, if not exclusively, in phosphodiester linkages in the outer chains of the wall mannan. Losses of other wall components following HF treatment, with the exception of the protein from walls of strain NCYCIO63, were very small and, with glucan, probably within the limits of error of the analytical method. The consistently larger decrease in the mannan content is probably attributable to the loss of mannose and mannobiosyl residues that were located distal to the phosphodiester linkages in the mannan side chains. The loss of protein from walls of strain NCYCI063 could mean that, in this strain, the mannan has a somewhat different structure from the polymer in other strains of the species, with protein being associated in some way with the mannan side-chains. That staining with fluorescein-conjugated concanavalin $\mathrm{A}$, which binds specifically to mannan in the wall (Tkacz et al., I97I), was not altered by treating any of the organisms with HF confirms that the bulk of the $\alpha$-linkages in the mannan are not affected by the treatment. However, HFtreated organisms were less able to bind fluorescein-conjugated antibody raised against strain NCYC366; this is almost certainly due to loss of terminal side-chain $\alpha$-D-mannopyranosyl phosphate units which are known to be immunological determinants in strains of S. cerevisiae (Raschke \& Ballou, 197I).

There did not appear to be any correlation between the contents of wall phosphorus and the sedimentation rates of untreated organisms of all four strains. Lyons \& Hough (I970 $b$ ) found that the outer layers of walls of strains NCYCIO05 and NCYCIO63 contained more phosphorus than the corresponding layers from the walls of non-flocculent organisms of

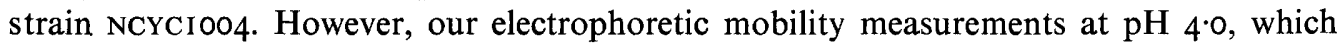
give a measure of the density of phosphate groups in the outer layers of the wall to a depth of $4.2 \mathrm{~nm}$ with buffer of ionic strength 0.005 (Eddy \& Rudin, 1958; Fisher, 1975), did not indicate any correlation between the phosphate contents of the outer layers of walls and the flocculation rate of organisms. Nor could the mobility attributable to protein (the mobility at $\mathrm{pH} 3.0$ subtracted from that at $\mathrm{pH} 7 \cdot 0$; Eddy \& Rudin, 1958) be correlated with sedimentation rates.

The increased flocculation rates shown by HF-treated organisms were rather surprising since removal of phosphodiester linkages from the wall mannan was expected, at least, not to increase the rate, and possibly to lower it. HF-treated organisms showed a very large decrease in mobility due to phosphate, and in some strains this mobility was completely absent. However, the decrease in the mobility attributable to protein in all strains was very much smaller. There was no indication with any of the strains that new ionogenic groups were exposed following HF treatment. While these findings may indicate that phosphodiester linkages in the wall mannan are not involved in cross-bridge formation during flocculation of S. cerevisiae, we still need to identify those anionic groups in the wall which may be involved in the cross-linking process, and to resolve why removing wall phosphomannan increases flocculation.

Our evidence suggests that carboxyl groups in the wall protein are involved in crosslinkages with $\mathrm{Ca}^{2+}$. The diminished ability of treated and untreated organisms to form flocs after they had been washed in deionized water or Io mM-EDTA, and the capacity of $\mathrm{Ca}^{2+}$ to restore floc-forming ability, suggest that $\mathrm{Ca}^{2}+$ ions are involved in bridge formation in both HF-treated and untreated organisms. The decrease in flocculation of untreated flocculent organisms and of HF-treated flocculent and non-flocculent organisms after exposure to the esterifying agent I,2-epoxypropane is evidence that the ionic groups involved are 
probably carboxyl groups in the wall protein. That treatment with the esterifying agent caused only a partial loss of floc-forming ability can be explained by the incomplete nature of the esterification process, as reported by Gittens \& James (I963). The decrease in flocculation following extraction of lipids could well be due to removal from the wall of hydrophobic proteins along with lipids-proteins that, despite their overall hydrophobic nature, may well contain a sufficiently large proportion of free carboxyl groups to play an important role in bridge formation.

The increased rate of sedimentation of HF-treated organisms is not caused by retention of $\mathrm{F}^{-}$in the wall following HF treatment as exposing untreated organisms to KF solution had no effect on flocculation, and indeed lowered it with organisms of strain NCYCI005. The most plausible explanation of the increased flocculation in HF-treated organisms is that it results from removal of the repulsive force created by the negative charges in the phosphodiester linkages which, in untreated organisms, help to keep organisms apart. Extending this hypothesis, we suggest that, in untreated flocculent organisms, there is a competition between the repulsive forces generated by the anionic groups (carboxyl as well as phosphodiester groups) and the attractive forces that arise when conditions are conducive for $\mathrm{Ca}^{2+}$ bridge formation between carboxyl groups in the wall proteins. When the attractive forces overcome the repulsive forces and a floc begins to form, the attraction of one cell to another is probably intensified by hydrogen bonding between mannose residues which lie distal to the phosphodiester on mannan side-chains in adjacent cells. Evidence for this last suggestion comes from the discovery that, whereas floc formation by untreated organisms is prevented by mannose, floc formation by HF-treated organisms of both $\mathrm{NCYCI}_{0} 63$ and $\mathrm{NCYC}_{3} 66$, which lack mannose residues distal to the excised phosphodiester linkages, is not prevented by mannose. Ballou (1974, 1976) has isolated a mutant of $S$. cerevisiae X2 I80 which lacks the ability to add mannose phosphate side-chains to the wall mannan. The availability of this mutant and of its parent appeared to offer a system with which to confirm our findings with untreated and HF-treated organisms. Unfortunately, the rate at which these haploid organisms sedimented was too low to permit accurate measurements to be made.

We are deeply indebted to A. R. Archibald (Department of Chemistry, University of Newcastle upon Tyne) for bringing to our notice the HF technique for excising phosphodiester linkages from polymers. Our thanks are also due to the Royal Society for making available funds to purchase a Cytopherometer, and to D. J. Fisher and G. G. Stewart for valuable discussion. One of us (P.M.J.) held a Colombo Plan Scholarship for which he is deeply grateful.

\section{REFERENCES}

Archibald, A. R., Baddiley, J. \& Shaukat, G. A. (I968). The glycerol teichoic acid from walls of Staphylococcus epidermidis. Biochemical Journal n10, 583-588.

Ballou, C. E. (1974). Some aspects of the structure, biosynthesis, and genetic control of yeast mannans. In Advances in Enzymology, vol. 40, pp. 239-270. Edited by A. Meister. New York: Wiley.

Ballou, C. E. (1976). Structure and biosynthesis of the mannan component of the yeast cell envelope. Advances in Microbial Physiology 14, 93-158.

Cawley, T. N., Harrington, M. G. \& LetTers, R. (1972). A study of the phosphate linkages in phosphomannan in cell walls of Saccharomyces cerevisiae. Biochemical Journal 129, 7 I I-726.

Chattaway, F. W., Holmes, M. R. \& Barlow, A. J. E. (I968). Cell wall composition of mycelial and blastospore forms of Candida albicans. Journal of General Microbiology 51, 367-376.

Chen, P. S., Toribara, T. Y. \& WARner, H. (1956). Microdetermination of phosphorus. Analytical Chemistry 28, I $756-1758$.

EDDY, A. A. (1955). Flocculation characteristics of yeasts. II. Sugars as dispersing agents. Journal of the Institute of Brewing 6r, 313-3 I8. 
EDDY, A. A. \& Rudin, A. D. (1958). Comparison of the respective electrophoretic and flocculation characteristics of different strains of Saccharomyces. Journal of the Institute of Brewing 64, I39-I42.

FisHeR, D. J. (1975). Flocculation - some observations on the surface charges of yeast cells. Journal of the Institute of Brewing 81, $107^{-1} 10$.

Fraser, A. R. \& RuSSELl, J. D. (I969). A spectrophotometric method for determination of cation-exchange capacity of clay minerals. Clay Minerals 8, 229-230.

GitTens, G. J. \& JAMES, A. M. (1963). Some physical investigations of the behaviour of bacterial surfaces. VI. Chemical modifications of surface components. Biochimica et biophysica acta 66, 237-249.

GlASER, L. \& BURGER, M. M. (1964). The synthesis of teichoic acids. III. Glucosylation of polyglycerophosphate. Journal of Biological Chemistry 239, 3 I87-319I.

Greenshields, R. N., Yates, J., Sharp, D. \& Davies, T. N. C. (1972). Studies in tower continuous fermentations. I. Methods for the characterization of flocculent yeasts. Journal of the Institute of Brewing $\mathbf{7 8}$, 236-242.

HARRIS, J. O. (1959). Possible mechanism of yeast flocculation. Journal of the Institute of Brewing 65, 5-6.

HUNTER, K. \& Rose, A. H. (1972). Lipid composition of Saccharomyces cerevisiae as influenced by growth temperature. Biochimica et biophysica acta $\mathbf{2 6 0}, 639-653$.

KLAUShofer, H. \& DorfwirTh, K. (I970). Mitteilungen der Versuchsanstalt für Gärungsgewerbe und des Instituts für angewandte Mikrobiologie 24 (2), 35-45.

Lyons, T. P. \& Hough, J. S. (I970a). Cation binding of yeast cell walls. Biochemical Journal I19, IoP.

Lyons, T. P. \& Hough, J. S. (1970 $b$ ). Flocculation of brewer's yeast. Journal of the Institute of Brewing 76 , 564-57I.

Lyons, T. P. \& Hough, J. S. (197I). Further evidence for the cross-bridging hypothesis for flocculation of brewer's yeast. Journal of the Institute of Brewing 77, 300-305.

McMurrough, I. \& Rose, A. H. (I967). Effect of growth rate and substrate limitation on the composition and structure of the cell wall of Saccharomyces cerevisiae. Biochemical Journal 105, 189-203.

Mill, P. J. (1964a). The effect of nitrogenous substances on the time of flocculation of Saccharomyces cerevisiae. Journal of General Microbiology 35, 53-60.

MILL, P. J. $(1964 b)$. The nature of the interactions between flocculent cells in the flocculation of Saccharomyces cerevisiae. Journal of General Microbiology 35, 61-68.

Patching, J. W. \& Rose, A. H. (I970). The effects and control of temperature. In Methods in Microbiology, vol. 2, pp. 23-38. Edited by J. R. Norris and D. W. Ribbons. London : Academic Press.

Rainbow, C. (I970). Brewer's yeasts. In The Yeasts, vol. 3, pp. I47-224. Edited by A. H. Rose and J. S. Harrison. London: Academic Press.

RASCHKE, W. C. \& BALLOU, C. E. (I97I). Immunochemistry of the phosphomannan of the yeast Kloeckera brevis. Biochemistry, New York ro, 4I30-4I35.

RICHARDS, M. \& Cowland, T. W. (1967). The rapid detection of brewery contaminants belonging to the genus Saccharomyces by a serological technique. Journal of the Institute of Brewing 73, 552-558.

SHaw, N. \& StEAd, A. (I974). The reaction of phosphoglycolipids and other lipids with hydrofluoric acid. Biochemical Journal $\mathbf{1 4 3}, 46 \mathrm{I}-464$.

SOMERS, E. \& FISHER, D. J. (I967). Effect of dodine acetate on the electrophoretic mobility of Neurospora crassa conidia. Journal of General Microbiology 48, I47-154.

Stewart, G. G. (I975). Yeast flocculation. Brewer's Digest March, 42-57.

Stewart, G. G., Rússell, I. \& Garrison, I. F. (I975). Some considerations of the flocculation characteristics of ale and lager yeast strains. Journal of the Institute of Brewing 81, 248-257.

Tkacz, J. S., Cybulska, E. B. \& LAMPEN, J. O. (I971). Specific staining of wall mannan in yeast cells with fluorescein-conjugated concanavalin A. Journal of Bacteriology ro5, I-5.

Wickerham, L. J. (I95I). Taxonomy of yeasts. I. Techniques of classification. United States Department of Agriculture Technical Bulletin no. I029. Washington, U.S.A. : U.S. Department of Agriculture. 